\title{
Ventricular fibrillation associated with complete right bundle branch block
}

\author{
Yoshiyasu Aizawa, MD*, Seiji Takatsuki, MD*, Takehiro Kimura, MD*, Nobuhiro Nishiyama, \\ MD*, Kotaro Fukumoto, MD*, Yoko Tanimoto, MD*, Kojiro Tanimoto, MD*, Shunichiro \\ Miyoshi, MD ${ }^{\star}$, Makoto Suzuki, MD ${ }^{\dagger}$, Yasuhiro Yokoyama, MD ${ }^{\ddagger}$, Masaomi Chinushi, MD $\S$, \\ Ichiro Watanabe, MD, FHRS", Satoshi Ogawa, MDI, Yoshifusa Aizawa, MD\#, Charles \\ Antzelevitch, PhD, FHRS ${ }^{\star *}$, and Keiichi Fukuda, MD* \\ "Department of Cardiology, School of Medicine, Keio University, Tokyo, Japan \\ tDepartment of Cardiology, Kameda Medical Center, Chiba, Japan \\ ¥Heart Rhythm Center, Tokyo Medical and Dental University, Tokyo, Japan \\ $\S$ Graduate School of Medical and Dental Science, Niigata University, Niigata, Japan \\ "School of Medicine, Nihon University, Itabashi Hospital, Tokyo, Japan \\ IInternational University of Health and Welfare, Mita Hospital, Tokyo, Japan \\ \#Division of Research and Development, Tachikawa Medical Center, Niigata, Japan \\ ${ }^{* *}$ Masonic Medical Research Laboratory, Utica, NY
}

\section{Abstract}

BACKGROUND-A substantial number of patients with idiopathic ventricular fibrillation (IVF) present with no specific electrocardiographic (ECG) findings.

OBJECTIVE-To evaluate complete right bundle branch block (RBBB) in patients with IVF.

METHODS-Patients with IVF showing complete RBBB were included in the present study. Structural and primary electrical diseases were excluded, and provocation tests were performed to exclude the presence of spastic angina or Brugada syndrome (BrS). The prevalence of complete RBBB and the clinical and ECG parameters were compared either in patients with IVF who did not show RBBB or in the general population and age and sex comparable controls with RBBB.

RESULTS-Of 96 patients with IVF, 9 patients were excluded for the presence of BrS. Of 87 patients studied, 10 (11.5\%) patients showed complete RBBB. None had structural heart diseases, $\mathrm{BrS}$, or coronary spasms. The mean age was $44 \pm 15$ years, and 8 of 10 patients were men. Among the ECG parameters, only the QRS duration was different from that of the other patients with IVF who did not show complete RBBB. Ventricular fibrillation recurred in 3:2 in the form of storms, which were well suppressed by isoproterenol. Complete RBBB was found less often in control subjects $(1.37 \% ; P<.0001)$, and the QRS duration was more prolonged in patients with IVF: 139 $\pm 10 \mathrm{~ms}$ vs $150 \pm 14 \mathrm{~ms}(P=.0061)$.

CONCLUSIONS-Complete RBBB exists more often in patients with IVF than in controls. A prolonged QRS complex suggests a conduction abnormality. Our findings warrant further investigation of the role of RBBB in the development of arrhythmias in patients with IVF.

(C) 2013 Heart Rhythm Society. All rights reserved.

Address reprint requests and correspondence: Dr Yoshiyasu Aizawa, Department of Cardiology, School of Medicine, Keio University, 35 Shinanomachi, Shinjuku-ku, Tokyo 160-8582, Japan. yoshiyaaizawa-circ@umin.ac.jp. 


\section{Keywords}

Sudden death; Idiopathic ventricular fibrillation; Right bundle branch block; Electrocardiogram; Brugada syndrome

\section{Introduction}

Ventricular fibrillation (VF) occurring in subjects without a specific definitive diagnosis or known mechanism is referred to as idiopathic ventricular fibrillation (IVF). Brugada syndrome (BrS), a type of IVF, exhibits a spontaneous ST-segment elevation in the right precordial leads $\left(\mathrm{V}_{1}-\mathrm{V}_{3}\right)$ as a diagnostic electrocardiographic (ECG) marker. ${ }^{1,2}$ In other cases, prominent $\mathbf{J}$ waves or $\mathbf{J}$ point elevation in the inferior and/or lateral precordial leads has been shown to be associated with an increased risk for ventricular tachycardia (VT)/ VF. ${ }^{3-7}$ However, a substantial number of patients with IVF show no such characteristic signs on their ECGs. ${ }^{4,7}$

A normal ECG is usually a requirement for defining a VF as "idiopathic," and therefore right bundle branch block (RBBB) would be one of the exclusion criteria for IVF. However, we recently encountered a patient with IVF who showed complete RBBB as the sole abnormal finding. Structural heart diseases were ruled out, and the presence of $\mathrm{BrS}$ and coronary spasms was excluded by provocation tests. The patient developed a VF storm, which responded to isoproterenol, as reported in the cases of $\mathrm{BrS}$ and other $\mathrm{J}$ wave syndromes. ${ }^{8-10}$

We undertook a case-control study, with the aim to assess the prevalence of RBBB and clinical characteristics in a series of patients with IVF. The prevalence of complete RBBB and its ECG characteristics were compared against the general population.

\section{Methods}

\section{Study population}

The study included patients admitted to 6 hospitals from April 1998 to March 2012 in whom VF was documented along with the absence of structural heart disease. All the initial episodes of VF occurred out of hospital and were defibrillated by emergency personnel. None of the VF episodes were precipitated by fever or other transient conditions. All patients met the following entry criteria:

1. a documented episode of VF at the time of cardiac arrest or after admission;

2. the absence of structural heart disease and the presence of normal cardiac function;

3. negative serology tests for inflammatory diseases (white blood cell, C-reactive protein, erythrocyte sedimentation rate) and no abnormal blood chemistry;

4. absence of coronary artery disease or coronary spasm; and

5. no known primary electrical diseases, which include long or short QT intervals, catecholaminergic polymorphic VT, ${ }^{11}$ and Wolff-Parkinson-White syndrome.

\section{Cardiac catheterization and electrophysiological study}

Cardiac catheterization was performed to exclude structural heart diseases and coronary artery diseases. Coronary spasm was excluded by a negative provocation test using either acetylcholine or ergometrine. Briefly, after the exclusion of significant stenosis, acetylcholine was injected into the left coronary artery in incremental doses of 50 and 100 
$\mathrm{mg}$ (in $10 \mathrm{~mL}$ of $0.9 \%$ saline) over 20 seconds. Acetylcholine was then injected into the right coronary artery, as described above. If acetylcholine did not induce coronary spasms, $50 \mathrm{mg}$ of intracoronary ergonovine maleate was injected into the right coronary artery and the left coronary artery over a period of 5 minutes. The end point was the development of total or subtotal occlusion or the completion of drug infusion. ${ }^{12}$

\section{Exclusion}

BrS was excluded by the absence of the type 1 ST-T pattern in leads $\mathrm{V}_{1}-\mathrm{V}_{3}$ and those patterns recorded at the second intercostal space as well as by the lack of induction of type 1 ECG by class I drugs. ${ }^{2,13}$ The dosages of the drugs used in provocation testing for $\mathrm{BrS}$ were as follows: pilsicainide $1 \mathrm{mg} / \mathrm{kg} / 10 \mathrm{~min} \mathrm{IV}$, flecainide $400 \mathrm{mg}$ p.o., and procainamide 10 $\mathrm{mg} / \mathrm{kg} / 10 \mathrm{~min}$ IV. The end point was the development of type $1 \mathrm{BrS}$ ECG pattern or the completion of drug infusion. Coronary spasm was excluded by a negative provocation test using acetylcholine and/or ergometrine.

Catecholaminergic polymorphic VT was ruled out by patient's history, infusion of isoproterenol at electrophysiological study (EPS), or exercise stress testing. Short and long QT syndromes were excluded by ECG findings. Invasive studies and provocation tests were performed after obtaining written and informed consent.

\section{Controls}

The control group consisted of 4092 men and 3185 women between 20 and 69 years of age, who underwent annual health examinations in our clinic. All subjects showed normal results on physical examination and exhibited no overt heart failure. When abnormal findings were uncovered, the presence of cardiac disease was ruled out by echocardiography or exercise stress testing. Sudden cardiac death was ruled out in all the members of the subject's family.

The prevalence of complete RBBB was determined for each decade of life for comparison with that in patients with IVF. From the subjects showing complete RBBB, 55 of comparable age and sex were randomly chosen and the ECG parameters were compared with those of patients with IVF who showed RBBB.

\section{Definition}

Complete RBBB was defined as a late $R\left(R^{\prime}\right)$ wave presenting in lead $V_{1}$ or $V_{2}$ with a slurred $\mathrm{S}$ wave in leads I and/or in lead $\mathrm{V}_{6}$ with a prolonged QRS duration of $>120 \mathrm{~ms}$. The QRS duration was measured from the beginning of the QRS complex to the J point, which was defined as the point of transition from the $\mathrm{R}$ wave to the ST segment. ${ }^{4,5,14}$

The diagnoses of BrS and early repolarization were based on the consensus report, ${ }^{2,13}$ and $\mathrm{J}$ waves were positive if the J point showed an amplitude of $\searrow 0.1 \mathrm{mV}$ above the isoelectric line in at least 2 contiguous leads in the inferior or precordial leads or in lead I or aVL. ${ }^{3-7}$

\section{ECG interpretation and data analysis}

If patients who showed complete RBBB were identified in patients with IVF who met all the inclusion criteria, then $\mathrm{BrS}$ or other electrical diseases were ruled out. ECGs were read by 2 cardiologists to diagnose complete RBBB, BrS, and early repolarization syndrome (ERS). For ECGs with discrepant interpretations, a consensus was reached by a discussion between the 2 readers.

The ECG parameters were compared between patients with IVF who showed RBBB and patients with IVF who did not show RBBB for the basic rhythm and the RR, PR, and QT intervals in a standardized manner; the QT interval was corrected by using the Bazett 
formula. ${ }^{15}$ The prevalence of complete RBBB and ECG parameters were compared with those of controls.

\section{Statistical analysis}

Numerical values are expressed as mean \pm SD, and categorical variables are expressed either as absolute numbers or as a percentage. The differences between groups were analyzed by using the Mann-Whitney-Wilcoxon test for continuous variables and the Pearson $x^{2}$ test for categorical variables. Statistical analyses were performed with SPSS, version 12.0 (SPSS Inc, Chicago, IL). A 2 -sided $P$ value of $<.05$ was considered statistically significant. The study was approved by the internal board of the School of Medicine at Keio University.

\section{Results}

\section{Patients with IVF who showed RBBB}

From 1998 to 2011, we evaluated 96 patients with IVF, 12 of whom showed RBBB on admission. No structural heart disease was detected. In 2 patients, BrS was diagnosed from the appearance of the type $1 \mathrm{ST}$-segment elevation in the right precordial leads, which was disclosed via spontaneous appearance of typical 1 ST-segment elevation in one patient (Figure 1$)^{16}$ and after use of a class Ic drug in the other. The remaining $10(11.4 \%)$ patients were included in the present study. A diagnostic ECG pattern of $\mathrm{BrS}$ was not induced in 9 patients who received a sodium block challenge: pilsicainide in 6 patients, flecainide in 2 patients, and procainamide in 1 patient. One patient was not tested, but repeated ECGs that included higher intercostal space recording were negative for BrS during her hospitalization. None of the patients had symptoms suggestive of chest pain, and they were negative on exercise stress test. Provocation of a coronary spasm was negative in all 8 patients tested. At EPS, programmed electrical stimulation induced VF in 5 of 7 patients studied.

The patient characteristics are summarized in Table 1 . The mean age of the patients was 44 \pm 15 years (range $21-66$ years), and 8 of 10 patients were men. VF occurred in the early morning $(n=4)$, evening $(n=2)$, around midnight $(n=3)$, or in the daytime $(n=1)$.

\section{ECG of patients with IVF who showed RBBB}

An $R^{\prime}$ wave in lead $V_{1}$ and a slurred $S$ wave in lead $V_{6}$ or I were observed in 9 patients (cases 1-9), and 1 patient showed an $r^{\prime}$ or $s$ wave in lead $V_{1}$ but showed an $R^{\prime}$ wave in lead $\mathrm{V}_{2}$ (Figure 2). The QRS duration was $>120 \mathrm{~ms}$ in all patients: $150 \pm 14 \mathrm{~ms}$. Three patients displayed a mild prolongation of the PR interval of $\geq 0.20$ seconds. Left axis deviation of the frontal electrical axis $>30^{\circ}$ was observed in 2 patients. $\mathrm{J}$ wave-like defections were observed in the inferior leads in 4 patients (cases 3, 4, 6, and 8 in Figure 2) within the widened QRS complexes. In 1 patient, a partial resolution of RBBB occurred during EPS, which led to the appearance of $\mathrm{J}$ waves in leads $\mathrm{I}$ and $\mathrm{aVL}$ (Figure 3).

\section{Comparisons between patients with IVF who showed RBBB and patients who did not show RBBB}

The age of 10 patients with IVF who showed RBBB was higher but nonsignificant compared with remaining 77 patients with IVF: $44 \pm 15$ years vs $38 \pm 14$ years, respectively $(P=.2713)$. The ECG parameters were similar between the 2 groups except for the QRS duration (Table 2). RBBB resulted in only a slight prolongation of the QT interval, as shown in lead II.

Typical J waves were observed at the terminal part of the QRS complex in 42 of 77 (54.5\%) patients with IVF who did not show RBBB as reported earlier. ${ }^{4,7} \mathrm{~J}$ wave-like defections 
were found to be buried within the QRS complexes in the inferior leads in 4 of our 10 (40\%) patients with RBBB (Figure 2).

\section{RBBB in controls}

Complete RBBB was found in $1.37 \%$ of 7277 subjects: $2.00 \%$ in male subjects $(\mathrm{n}=4092)$ and $0.57 \%$ in female subjects $(\mathrm{n}=3185)$. Complete RBBB increased with advancing age: $1.32 \%, 1.15 \%, 1.36 \%, 2.37 \%$, and $3.66 \%$ for men and $0.00 \%, 0.68 \%, 0.51 \%, 0.58 \%$, and $0.87 \%$ for women, respectively, for the third to seventh decades. Therefore, the prevalence of complete RBBB was higher in patients with IVF than in healthy controls $(P<.0001)$. Electrographically, $\mathrm{J}$ wave-like notches were found in $29.0 \%$ of the control subjects with complete RBBB and in $40.0 \%$ of the patients with IVF who showed complete RBBB. The difference was not significant $(P=.4999)$. Left axis deviation in frontal electrical axis was found in $10.0 \%$ vs $20.0 \%$ for controls and patients with IVF, respectively $(P=.2980)$.

Among the ECG parameters, only the QRS duration was different ( $P=.0061$; Table 2$)$. The QT interval was prolonged in controls $(P=.0386)$, but the corrected QT interval was not $(P$ $=.3740$ ).

\section{Course in hospital and outcomes}

One patient rejected both further examination and the implantation of an implantable cardioverter-defibrillator (ICD), and the remaining patients were followed for $6.3 \pm 2.5$ years. Seven patients underwent ICD implantation, and 3 of these patients had VF recurrence, 2 in a state of VF storms that were controlled by isoproterenol infusion. VF was precipitated by short-coupled premature ventricular complexes (PVCs; Figure 4). One of 2 patients with VF storms received bepridil for chronic therapy, and the other was followed without antiarrhythmic drug therapy. Both had been free from VF recurrence. ${ }^{17,18}$ One patient was lost to follow-up, and the remaining patients survived.

\section{Discussion}

Ten patients were admitted for VF, and in all of them, structural heart diseases and primary electrical diseases including $\mathrm{BrS}$ and coronary spasms were excluded and were diagnosed to have IVF. Complete RBBB was the sole abnormal finding. VF recurred in 3, and a VF storm was controlled by isoproterenol that suggested a common underlying arrhythmogenic substrate to BrS or J wave-associated IVF. Furthermore, the prevalence of complete RBBB was higher, and the QRS duration in patients with IVF was prolonged than the control subjects who showed complete RBBB.

The higher prevalence of complete RBBB was confirmed in patients with VF compared to controls. In the literature, we can count 93 patients with IVF in whom the ECG findings were well described. ${ }^{19-24}$ Among them, 9 of 93 (9.7\%) patients showed complete RBBB, which is similar to our finding: $12.5 \%$. However, it is possible that some patients might have $\mathrm{BrS}$. This is because most of them were diagnosed before 1992 while $\mathrm{BrS}$ was first reported in that year. ${ }^{1}$ However, even in a recent report, Nam et $\mathrm{al}^{25}$ included 1 patient with RBBB to non-BrS-type IVF on the basis of rigid criteria.

Although complete RBBB has generally been considered to be benign, ${ }^{14,26-30}$ a recent cohort study made it apparent that RBBB is associated with both cardiovascular risk and allcause mortality. ${ }^{31}$ Furthermore, recent studies have reported that complete RBBB can conceal the BrS ECG phenotype, which can be unmasked when RBBB is resolved. ${ }^{16,32}$ Twelve-lead ECGs were recorded at least once every other day, including those during drug testing, exercise testing, or catheterization, which were performed on different days. ECGs at higher intercostal spaces were performed on another occasion of ECG recording. If 
present, BrS would be highly disclosed by these repeatedly recorded ECGs.

Notwithstanding, it will be difficult to totally dismiss the possibility that RBBB may have concealed the $\mathbf{J}$ wave manifestation in our patients with IVF. Pacing at the right ventricle might be used to resolve the RBBB pattern and disclose J waves (Figure 3).

Ameliorative response to isoproterenol, but not to beta-blockers, amiodarone, and sedative agents might provide a clue to the underlying arrhythmogenic substrate. These responses are consistent with those observed in patients with $\mathrm{J}$ wave syndromes. ${ }^{33}$ Isoproterenol is known to normalize ST-segment elevation and to suppress VF in patients with $\mathrm{BrS}$ and other J wave syndromes. ${ }^{4,6,9,10,25}$ This can be explained by the fact that isoproterenol produces an inward shift in the balance of currents during the early phases of the action potential by increasing inward calcium currents. ${ }^{33}$ So far, VF episodes were observed to be commonly initiated by PVCs with short coupling intervals and following a short-long-short sequence. ${ }^{25,34}$ Two of 3 patients showed PVCs with short coupling intervals (Figure 4). These observations prompt further speculation that complete RBBB may conceal ERS. ${ }^{33}$

\title{
Study limitations
}

Although Chiale et al ${ }^{32}$ reported a useful maneuver to distinguish $\mathrm{BrS}$ in patients with RBBB, we have not performed "Chiale's maneuver" in all patients. We need to collect this information from patients who were implanted with an ICD by using its pacing modality. Also, a recent study shows that the sternum appears to be the best location to detect the STsegment elevation, ${ }^{35}$ but we did not include recordings from the sternum at the third and second intercostal space. Furthermore, a drug challenge to unmask BrS was done by using procainamide, but the drug is notoriously known to be less sensitive than flecainide or pilsicainide. Therefore, for this purpose we have discontinued this drug.

In summary, contrary to common perceptions, it is likely that some patients with IVF also present with complete RBBB. A diagnosis of IVF in a survivor of VF is most of the time made by exclusion. Our study suggests that RBBB may still be compatible with this diagnosis, although patients with IVF are considered not to present with any abnormalities. To rule out concealed BrS or ERS in the presence of complete RBBB, right ventricle pacing during EPS or from ICD lead may be useful.

\section{Conclusions}

Our results demonstrate that complete RBBB is more common in patients with IVF than expected in the general population. From wider QRS complexes, advanced conduction abnormality was suggested, and pharmacologically, it was suggested to share common characteristics with BrS or J wave-associated IVF. The role of RBBB on the arrhythmogenesis needs to be further elucidated.

\section{Acknowledgments}

This work was supported by MEXT KAKENHI grant 23790873 (to Dr Aizawa), National Institutes of Health grant HL47678 (to Dr Antzelevitch), NYSTEM grant C026424 (to Dr Antzelevitch), and the Masons of New York, Florida, Massachusetts, and Connecticut.

We are grateful to Vincent Ventimiglia for his linguistic advice.

\section{ABBREVIATIONS}

\author{
BrS Brugada syndrome \\ ECG electrocardiogram/ electrocardiographic
}




$\begin{array}{ll}\text { EPS } & \text { electrophysiological study } \\ \text { ERS } & \text { early repolarization syndrome } \\ \text { ICD } & \text { implantable cardioverter-defibrillator } \\ \text { IVF } & \text { idiopathic ventricular fibrillation } \\ \text { PVC } & \text { premature ventricular complex } \\ \text { RBBB } & \text { right bundle branch block } \\ \text { VF } & \text { ventricular fibrillation } \\ \text { VT } & \text { ventricular tachycardia }\end{array}$

\section{References}

1. Brugada P, Brugada J. Right bundle branch block, persistent ST segment elevation and sudden cardiac death: a distinct clinical and electrocardiographic syndrome. A multicenter report. J Am Coll Cardiol. 1992; 20:1391-1396. [PubMed: 1309182]

2. Antzelevitch C, Brugada P, Borggrefe M, et al. Brugada syndrome: report of the second consensus conference. Heart Rhythm. 2005; 2:429-440. [PubMed: 15898165]

3. Aizawa Y, Tamura M, Chinushi M, et al. Idiopathic ventricular fibrillation and bradycardiadependent intraventricular block. Am Heart J. 1993; 126:1473-1474. [PubMed: 8249808]

4. Haissaguerre M, Derval N, Sacher F, et al. Sudden cardiac arrest associated with early repolarization. N Engl J Med. 2008; 358:2016-2023. [PubMed: 18463377]

5. Rosso R, Kogan E, Belhassen B, et al. J-point elevation in survivors of primary ventricular fibrillation and matched control subjects: incidence and clinical significance. J Am Coll Cardiol. 2008; 52:1231-1238. [PubMed: 18926326]

6. Nam GB, Kim YH, Antzelevitch C. Augmentation of J waves and electrical storms in patients with early repolarization. N Engl J Med. 2008; 358:2078-2079. [PubMed: 18463391]

7. Aizawa Y, Sato A, Watanabe H, et al. Dynamicity of the J-wave in idiopathic ventricular fibrillation with a special reference to pause-dependent augmentation of the J-wave. J Am Coll Cardiol. 2012; 59:1948-1953. [PubMed: 22624834]

8. Watanabe A, Fukushima Kusano K, Morita H, et al. Low-dose isoproterenol for repetitive ventricular arrhythmia in patients with Brugada syndrome. Eur Heart J. 2006; 27:1579-1583. [PubMed: 16760208]

9. Bernard A, Genee O, Grimard C, Sacher F, Fauchier L, Babuty D. Electrical storm reversible by isoproterenol infusion in a striking case of early repolarization. J Intervent Card Electrophysiol. $2009 ; 25: 123-127$.

10. Haissaguerre M, Sacher F, Nogami A, et al. Characteristics of recurrent ventricular fibrillation associated with inferolateral early repolarization role of drug therapy. J Am Coll Cardiol. 2009; 53:612-619. [PubMed: 19215837]

11. Priori SG, Napolitano C, Memmi M, et al. Clinical and molecular characterization of patients with catecholaminergic polymorphic ventricular tachycardia. Circulation. 2002; 106:69-74. [PubMed: 12093772]

12. Sato A, Tanabe $\mathrm{Y}$, Chinushi $\mathrm{M}$, et al. Analysis of $\mathrm{J}$ waves during myocardial ischaemia. Europace. 2012; 14:715-723. [PubMed: 22037542]

13. Fujiki A, Usui M, Nagasawa H, Mizumaki K, Hayashi H, Inoue HST. Segment elevation in the right precordial leads induced with class Ic antiarrhythmic drugs: insight into the mechanism of Brugada syndrome. J Cardiovasc Electrophysiol. 1999; 10:214-218. [PubMed: 10090224]

14. Eriksson P, Hansson PO, Eriksson H, Dellborg M. Bundle-branch block in a general male population: the study of men born 1913. Circulation. 1998; 98:2494-2500. [PubMed: 9832497]

15. Postema PG, De Jong JS, Van der Bilt IA, Wilde AA. Accurate electrocardiographic assessment of the QT interval: teach the tangent. Heart Rhythm. 2008; 5:1015-1018. [PubMed: 18598957] 
16. Tomita M, Kitazawa H, Sato M, Okabe M, Anzelevitch C, Aizawa Y. Complete right bundle branch block masking brugada syndrome: a case. J Electrocardiol. 2012; 45:780-782. [PubMed: 22832153]

17. Sugao M, Fujiki A, Nishida K, et al. Repolarization dynamics in patients with idiopathic ventricular fibrillation: pharmacological therapy with bepridil and disopyramide. J Cardiovasc Pharmacol. 2005; 45:545-549. [PubMed: 15897781]

18. Murakami M, Nakamura K, Kusano KF, et al. Efficacy of low-dose bepridil for prevention of ventricular fibrillation in patients with Brugada syndrome with and without SCN5A mutation. J Cardiovasc Pharmacol. 2010; 56:389-395. [PubMed: 20625312]

19. Belhassen B, Shapira I, Shoshani D, Paredes A, Miller H, Laniado S. Idiopathic ventricular fibrillation: inducibility and beneficial effects of class I antiarrhythmic agents. Circulation. 1987; 75:809-816. [PubMed: 3829343]

20. Horowitz LN, Greenspan AM, Spielman SR, Josephson ME. Torsades de pointes: electrophysiologic studies in patients without transient pharmacologic or metabolic abnormalities. Circulation. 1981; 63:1120-1128. [PubMed: 7471373]

21. Josephson ME, Spielman SR, Greenspan AM, Horowitz LN. Mechanism of ventricular fibrillation in man: observations based on electrode catheter recordings. Am J Cardiol. 1979; 44:623-631. [PubMed: 484493]

22. Morady F, Scheinman MM, Hess DS, Chen R, Stanger P. Clinical characteristics and results of electrophysiologic testing in young adults with ventricular tachycardia or ventricular fibrillation. Am Heart J. 1983; 106:1306-1314. [PubMed: 6650352]

23. Pedersen DH, Zipes DP, Foster PR, Troup PJ. Ventricular tachycardia and ventricular fibrillation in a young population. Circulation. 1979; 60:988-997. [PubMed: 487557]

24. Wever EF, Hauer RN, Oomen A, Peters RH, Bakker PF, Robles de Medina EO. Unfavorable outcome in patients with primary electrical disease who survived an episode of ventricular fibrillation. Circulation. 1993; 88:1021-1029. [PubMed: 8353864]

25. Nam GB, Ko KH, Kim J, et al. Mode of onset of ventricular fibrillation in patients with early repolarization pattern vs. Brugada syndrome. Eur Heart J. 2010; 31:330-339. [PubMed: 19880418]

26. Thrainsdottir IS, Hardarson T, Thorgeirsson G, Sigvaldason H, Sigfusson N. The epidemiology of right bundle branch block and its association with cardiovascular morbidity- the Reykjavik Study. Eur Heart J. 1993; 14:1590-1596. [PubMed: 8131755]

27. Hiss RG, Lamb LE. Electrocardiographic findings in 122,043 individuals. Circulation. 1962; 25:947-961. [PubMed: 13907778]

28. Fleg JL, Das DN, Lakatta EG. Right bundle branch block: long-term prognosis in apparently healthy men. J Am Coll Cardiol. 1983; 1:887-892. [PubMed: 6826977]

29. Fahy GJ, Pinski SL, Miller DP, et al. Natural history of isolated bundle branch block. Am J Cardiol. 1996; 77:1185-1190. [PubMed: 8651093]

30. Rotman M, Triebwasser JH. A clinical and follow-up study of right and left bundle branch block. Circulation. 1975; 51:477-484. [PubMed: 1132086]

31. Bussink BE, Holst AG, Jespersen L, Deckers JW, Jensen GB, Prescott E. Right bundle branch block: prevalence, risk factors, and outcome in the general population. Results from the Copenhagen City Heart Study. Eur Heart J. 2013; 34:138-146. [PubMed: 22947613]

32. Chiale PA, Garro HA, Fernandez PA, Elizari MV. High-degree right bundle branch block obscuring the diagnosis of Brugada electrocardiographic pattern. Heart Rhythm. 2012; 9:974-976. [PubMed: 22306100]

33. Antzelevitch C, Yan GX. J wave syndromes. Heart Rhythm. 2010; 7:549-558. [PubMed: 20153265]

34. Viskin S, Lesh MD, Eldar M, et al. Mode of onset of malignant ventricular arrhythmias in idiopathic ventricular fibrillation. J Cardiovasc Electrophysiol. 1997; 8:1115-1120. [PubMed: 9363814]

35. Veltmann C, Papavassiliu T, Konrad T, et al. Insights into the location of type I ECG in patients with Brugada syndrome: correlation of ECG and cardiovascular magnetic resonance imaging. Heart Rhythm. 2012; 9:414-421. [PubMed: 22119454] 
A

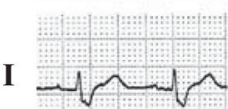

V1

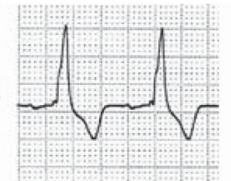

II

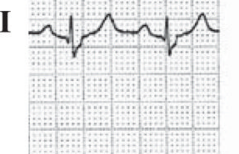

V2

III

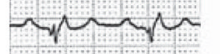

V3 -1 m in

aVR
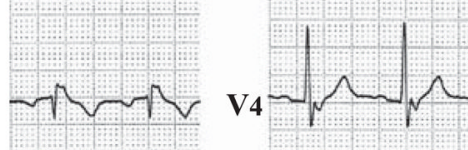

$\mathrm{aVL}$

aVF
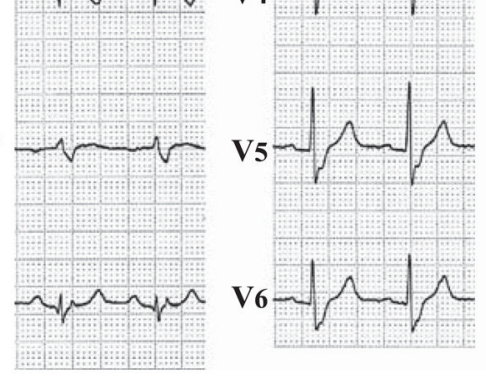

B

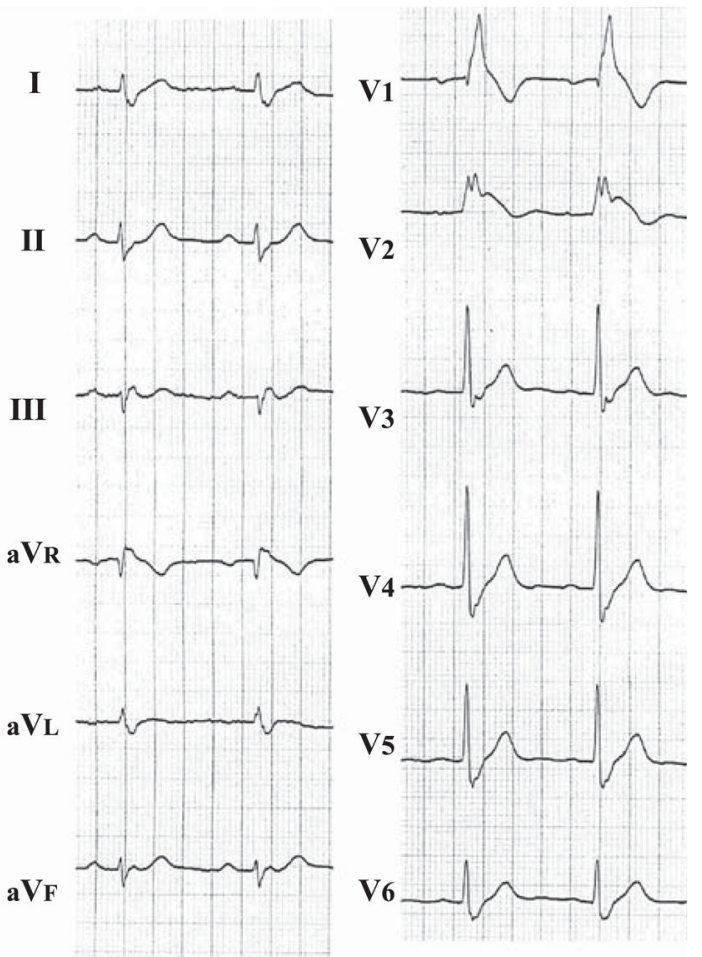

\section{Figure 1.}

A case of Brugada syndrome complicated with complete right bundle branch block (RBBB). The patient is a 69-year-old man (case 11). The electrocardiogram on admission (A) showed complete RBBB; however, a peculiar ST-segment pattern, which was considered to represent Brugada syndrome, was observed on repeated electrocardiographic recordings (B). The patient showed coved-type ST-segment elevation when RBBB resolved spontaneously, as reported elsewhere. ${ }^{16}$ 


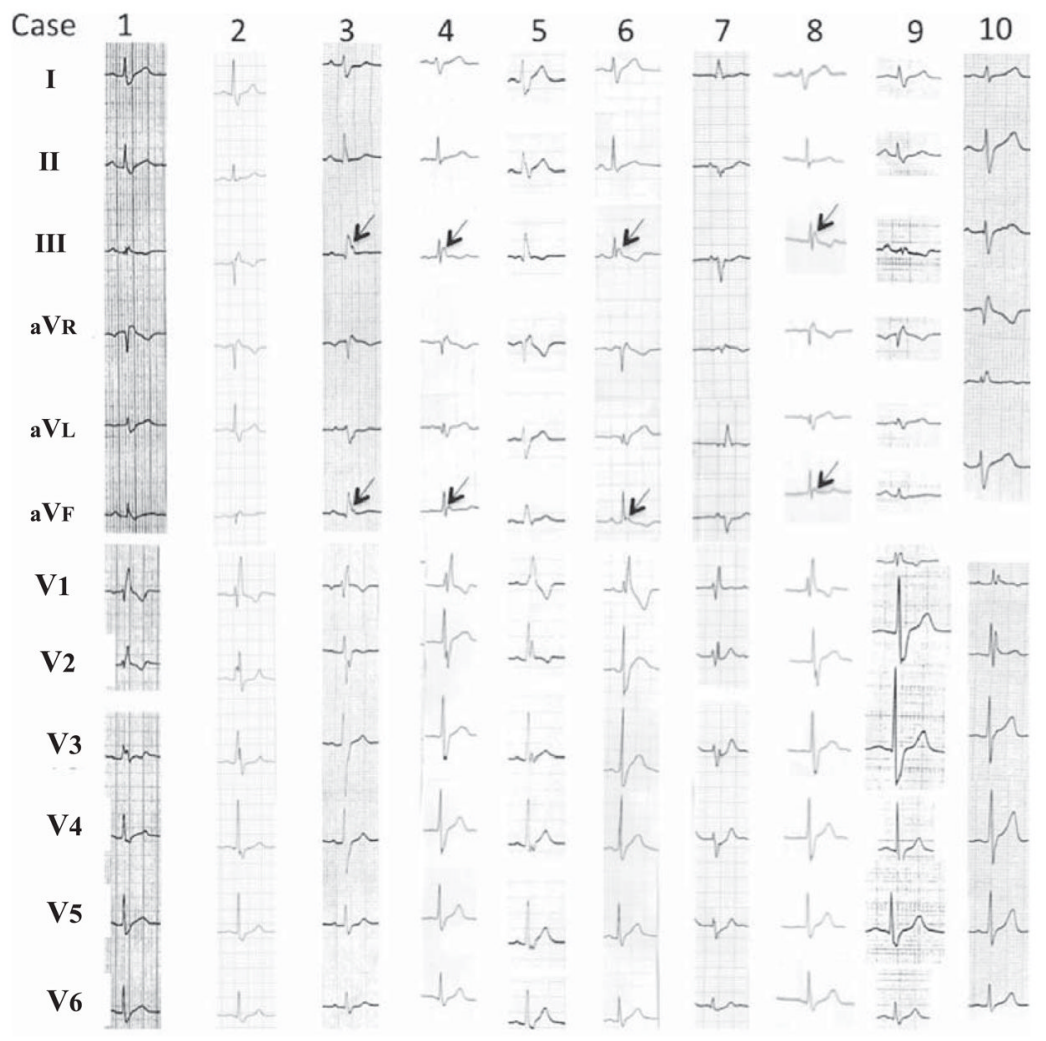

Figure 2.

Electrocardiograms of 10 patients with idiopathic ventricular fibrillation with right bundle branch block. A typical complete right bundle branch block pattern showing a late $\mathrm{R}$ wave in lead $V_{1}$ (cases 1-9) or lead $V_{2}$ (case 10) with a prolonged duration of the QRS complex of $>120 \mathrm{~ms}$ can be observed. Left axis deviation is obvious in cases 7 and 10 . J wave-like notches were observed in cases 3, 4, 6, and 8 (arrows) within the QRS complexes. 
A

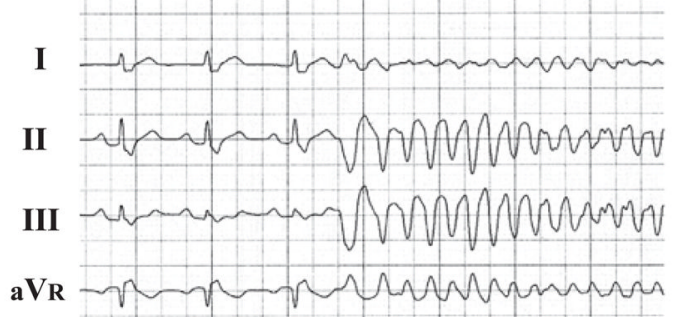

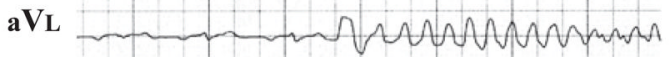

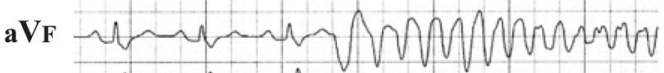
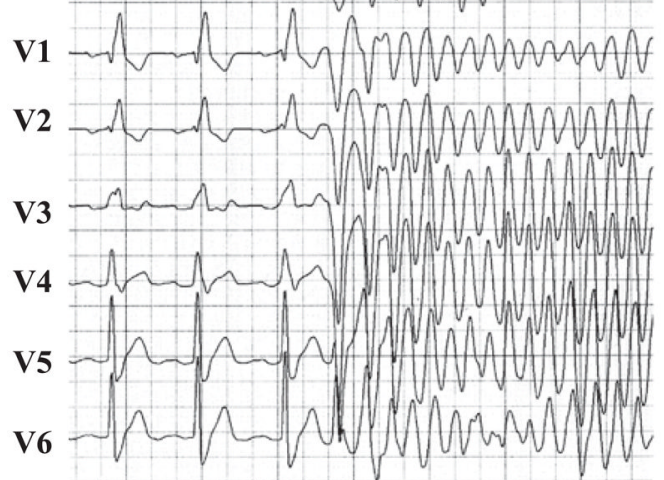

B

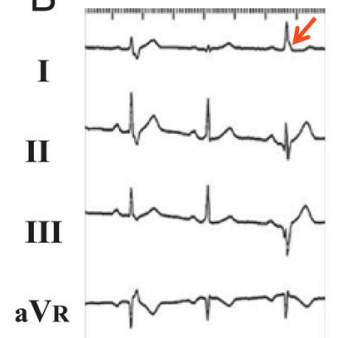

aVL

aVF
V1
V2

V2

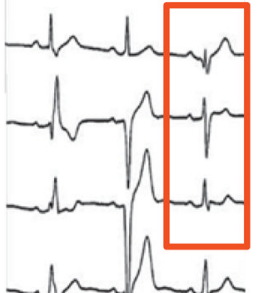

V4<smiles>C1CCC(CC2CCCCC(CC3CC3)C2)CC1</smiles>

V5

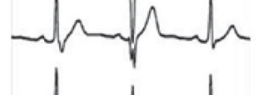

V6

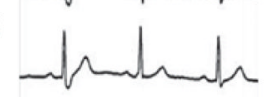

Figure 3.

Ventricular fibrillation (VF) onset and resolution of right bundle branch block (RBBB) during electrophysiological study. A: A 45-year-old man previously diagnosed as idiopathic ventricular fibrillation followed by implantable cardioverter-defibrillator implantation was admitted for a VF storm. The pilsicainide provocation test for both Brugada syndrome and coronary spasm was negative, but his ECG shows a typical pattern of complete RBBB: an R' wave in lead $V_{1}$ and a slurred $S$ wave in lead $V_{6}$ and other leads. A premature ventricular beat that originated from the inferobasal region of the right ventricle was repeatedly initiating the VF. B: During electrophysiological study, the degree of RBBB diminished after right ventricular pacing, which revealed $\mathrm{J}$ waves in lead I (arrow). 


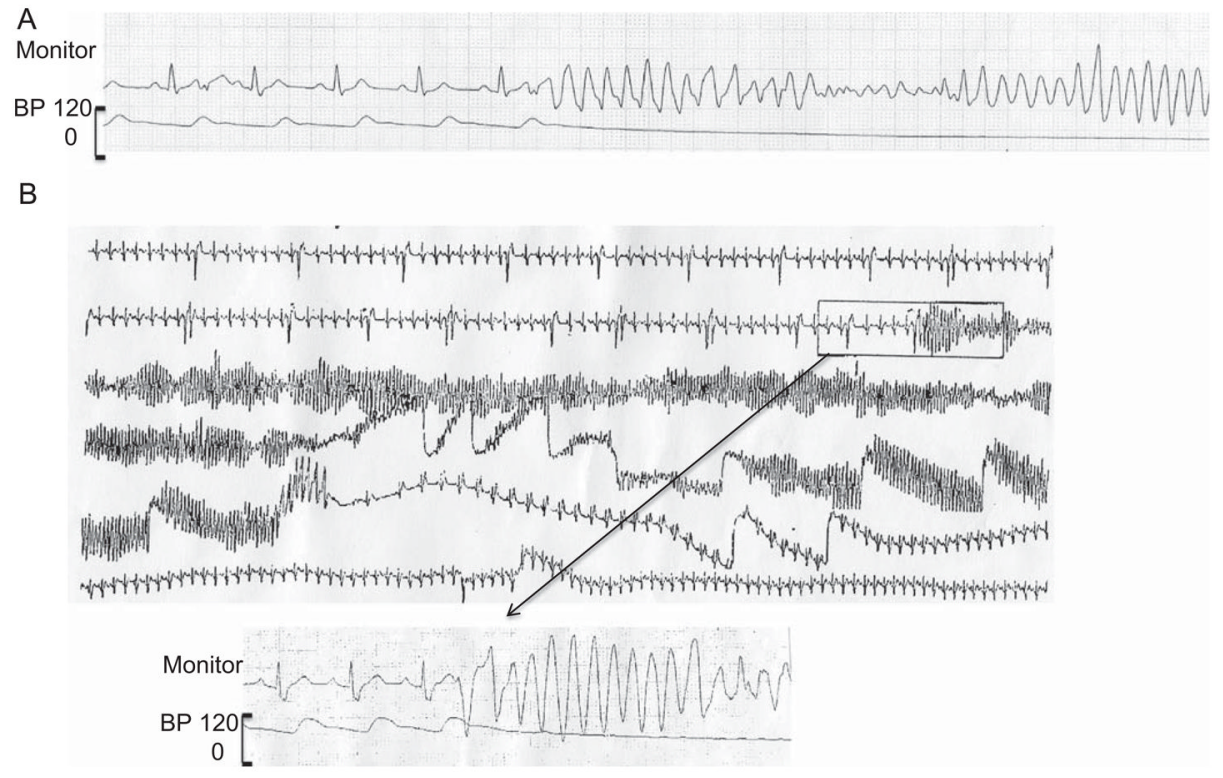

Figure 4.

Onset of ventricular fibrillation (VF). A: The patient was case 3. Soon after admission, VF occurred 11 times, initiated by short-coupled premature ventricular complex, and then VF subsided. B: The patient was case 4. VF occurred after admission and recorded on monitor electrocardiogram. The onset of VF was shown in the inset below, which showed premature ventricular complex with short coupling interval. 


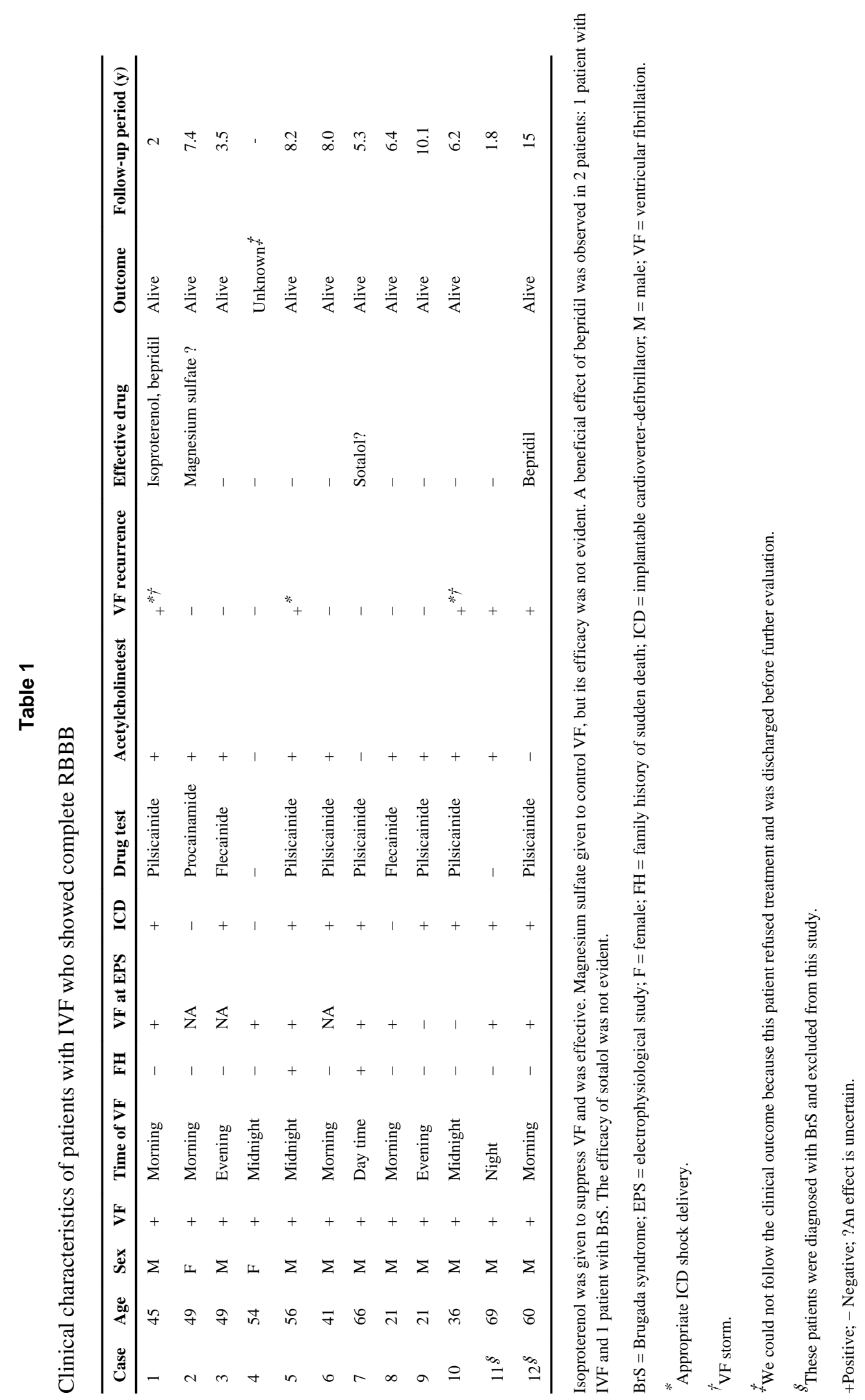

Heart Rhythm. Author manuscript; available in PMC 2014 July 01. 


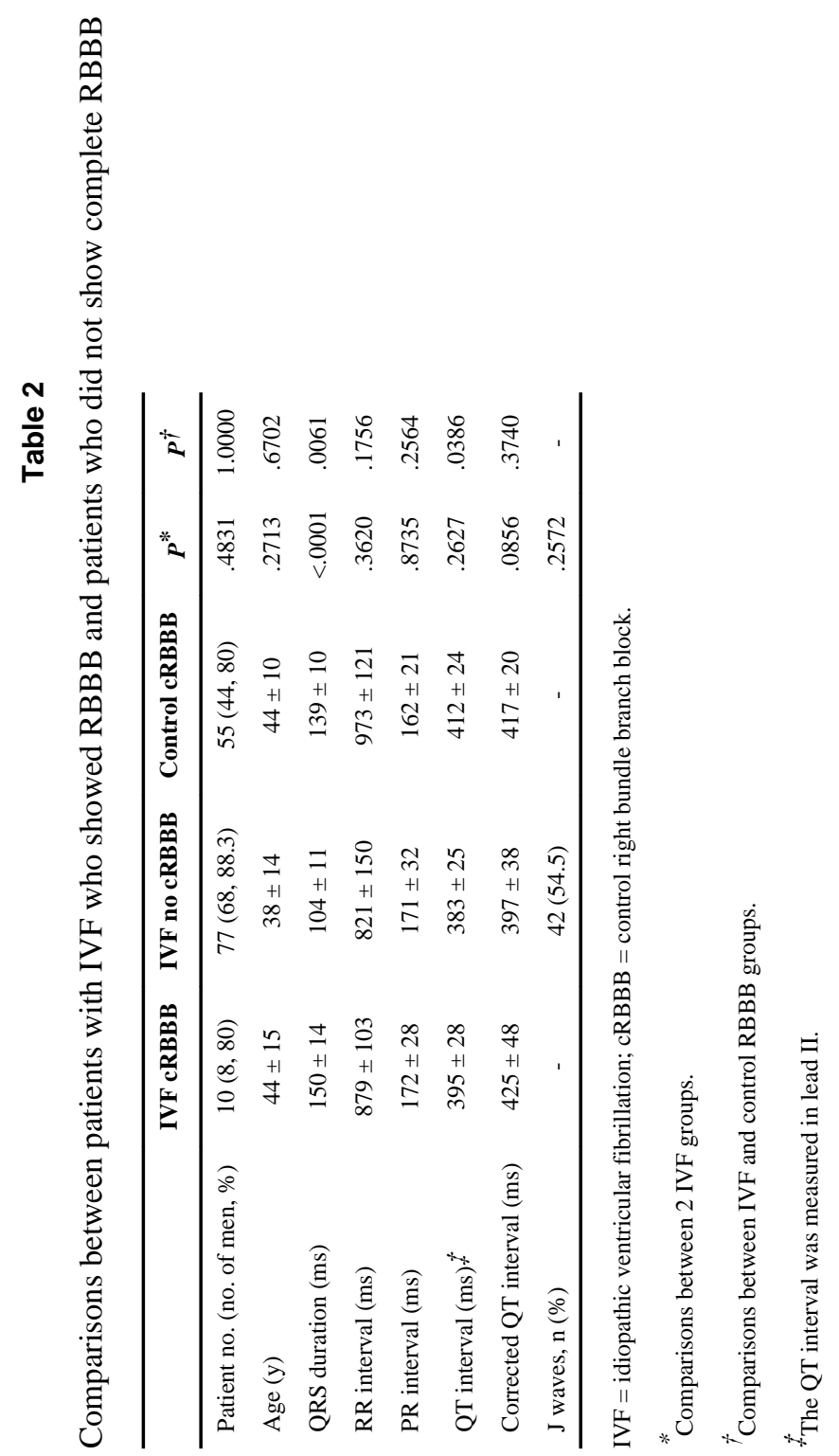

